\title{
Reliability of Displayed Tidal Volume in Healthy and Surfactant- Depleted Piglets
}

\author{
A Cecilia Mendiondo Luedloff MD, Tracy L Thurman, Shirley J Holt RRT, Shasha Bai PhD, \\ Mark J Heulitt MD FAARC, and Sherry E Courtney MD
}

\begin{abstract}
BACKGROUND: Volutrauma has been established as the key factor in ventilator-induced lung injury and can only be avoided if tidal volume $\left(V_{T}\right)$ is accurately displayed and delivered. The purpose of this study was to investigate the accuracy of displayed exhaled $V_{T}$ in a ventilator commonly used in small infants with or without a proximal flow sensor and using 3 methods to achieve a target $V_{T}$ in both a healthy and lung-injured neonatal pig model. METHODS: This was a prospective animal study utilizing 8 male pigs, approximately $2.0 \mathrm{~kg}$ (range $1.8-2.2 \mathrm{~kg}$ ). Intubated, sedated, neonatal pigs were studied with both healthy and injured lungs using the Servo-i ventilator. In pressure-regulated volume control, both with and without a proximal flow sensor, we used 3 methods to set $V_{T}$ : (1) circuit compliance compensation (CCC) on, set $V_{T}$ 6-8 mL/kg; (2) CCC off, calculated $V_{T}$ using the manufacturer's circuit compliance factor; and (3) CCC off, set $V_{T} 10-12 \mathrm{~mL} / \mathrm{kg}$ to approximate a target $V_{T}$ of 6-8 mL/kg. Ventilatordisplayed exhaled $V_{T}$ measurements were compared with exhaled $V_{T}$ measured at the airway opening by a calibrated pneumotachograph. Bland-Altman plots were constructed to show the level of agreement between the two. RESULTS: CCC improved accuracy and precision of displayed exhaled $V_{T}$ when the sensor was not used, more markedly in the lung-injured model. Without $C C C$, the sensor improved accuracy and precision of displayed exhaled $V_{T}$, again more markedly in the lung-injured model. CONCLUSIONS: When the Servo-i ventilator is used in neonates, $\mathrm{CCC}$ or the in-line sensor should be employed due to the large positive bias and imprecision seen with CCC off and no sensor in-line. Key words: respiratory care; mechanical ventilation; neonatal ventilation. [Respir Care 2016;61(12):1605-1612. (C) 2016 Daedalus Enterprises]
\end{abstract}

\section{Introduction}

Mechanical ventilation is a vital part of care delivered in the neonatal ICU; however, the risks of ventilation are well-known. Volutrauma has been established as the key

\footnotetext{
At the time of this research, Dr Courtney is affiliated with the Neonatology Section, and Dr Bai is affiliated with the Biostatistics Section, Department of Pediatrics, College of Medicine, University of Arkansas for Medical Sciences, Little Rock, Arkansas. Ms Holt is affiliated with the Respiratory Care Department, Arkansas Children's Hospital, Little Rock, Arkansas. At the time of this research, Dr Mendiondo Leudloff was with the Neonatology Section above; and Dr Heulitt and Ms Thurman were with the Critical Care Medicine Section. Currently Dr Mendiondo Leudloff is affiliated with The Women's Hospital, Newburgh, Indiana. Dr Heulitt is with Spence and Becky Wilson Baptist Children's Hospital, Memphis, Tennessee, and Ms Thurman is with the Translational Research Institute, UAMS, Little Rock, Arkansas.
}

factor in ventilator-induced lung injury and in addition may cause hypocarbia, which has been associated with neonatal brain injury, including periventricular leukomalacia and cerebral palsy. ${ }^{1,2}$

Several studies have demonstrated benefits of volumetargeted ventilation over pressure-limited ventilation in the

\footnotetext{
This work was supported in part by an intramural grant from the University of Arkansas for Medical Sciences College of Medicine Children's University Medical Group Grant Program.

Dr Courtney has disclosed a relationship with Salter Labs. The other authors have disclosed no conflicts of interest.

Dr Mendiondo Luedloff presented a version of this paper at the Pediatric Academic Societies Annual Meeting, held May 3-6, 2014, in Vancouver, Canada.
} 
neonatal population to reduce volutrauma. ${ }^{3,45}$ To optimize lung protection with this technique, clinicians must be able to accurately measure the tidal volume $\left(\mathrm{V}_{\mathrm{T}}\right)$ being delivered by the ventilator.

Neonatal ventilators vary in how $\mathrm{V}_{\mathrm{T}}$ is measured; some use a proximal flow sensor connected to the endotracheal tube, and others utilize a more distal sensor at the expiratory valve of the device itself. Neither method is ideal. Proximal flow sensors increase dead space, which can be particularly significant in smaller neonates with low $\mathrm{V}_{\mathrm{T}}$. Distal sensors may be inaccurate, due to the loss of gas volume delivered into the circuit. Toyama et $\mathrm{al}^{6}$ have demonstrated in neonatal test lung models that the actual $\mathrm{V}_{\mathrm{T}}$ delivered to the patient is significantly less than the $V_{T}$ delivered into the circuit by the ventilator. This gas volume may be lost due to compression of gas in the circuit and humidifier as well as distention of the breathing circuit.

Ventilators that measure $\mathrm{V}_{\mathrm{T}}$ distally use software to calculate for volume loss (circuit compliance compensation $[\mathrm{CCC}]$ ). Using the Servo 300 ventilator (SiemensElema, Solna, Sweden), Castle et $\mathrm{al}^{7}$ showed large inaccuracies in actual exhaled $\mathrm{V}_{\mathrm{T}}$ measurements with the use of CCC, particularly in small infants. Using a newer ventilator model (Servo-i, Solna, Sweden), Heulitt et al ${ }^{8}$ demonstrated more accurate exhaled $\mathrm{V}_{\mathrm{T}}$ measurement when using CCC in young pigs with normal lungs. An optional proximal flow sensor is also available for use in small infants but has not been studied or compared with CCC, yet some clinicians still instead prefer to estimate the effects of the circuit/humidity when setting $\mathrm{V}_{\mathrm{T}}$. This is of concern, because delivery of excessive or inappropriately small $\mathrm{V}_{\mathrm{T}}$ will lead to volutrauma or atelectrauma, respectively. Further, another study by Heulitt et al ${ }^{9}$ found differences in the measured compliance of the circuit as reported by the manufacturer and that measured by the ventilator. These differences were between 37 and $65 \%$ for the infant circuit and between 13 and $23 \%$ for the adult circuit.

The objective of this study was to investigate the accuracy of displayed exhaled $\mathrm{V}_{\mathrm{T}}$ using 3 different methods and comparing each with the accepted standard of a calibrated pneumotachograph. We used the Servo-i ventilator, which is commonly employed for neonatal ventilation in the United States and Europe. Both with and without a proximal flow sensor in-line, and in both the healthy and injured neonatal pig lung, we used 3 meth-

Correspondence: Sherry E Courtney MD, Department of Pediatrics, Arkansas Children's Hospital, One Children's Way, Slot 512-5, Little Rock, AR 72202. E-mail: scourtney@uams.edu.

DOI: $10.4187 /$ respcare.04569

\section{QUICK LOOK}

\section{Current knowledge}

Tidal volume $\left(\mathrm{V}_{\mathrm{T}}\right)$ must be accurately displayed and delivered to prevent ventilator-induced lung injury. Several ways of setting $\mathrm{V}_{\mathrm{T}}$ exist, especially with ventilators that may measure $V_{T}$ either exiting the ventilator or with a proximal flow sensor. The accuracy of these measurements in neonates has not been assessed.

\section{What this paper contributes to our knowledge}

Using the Servo-i ventilator, this study showed that, in a piglet model of both healthy and surfactant-depleted lungs, either the circuit compensation software or the proximal flow sensor may be employed. If neither option is utilized, large errors in displayed $\mathrm{V}_{\mathrm{T}}$ will exist.

ods to set $\mathrm{V}_{\mathrm{T}}$ : (1) CCC on, (2) CCC off with a calculated $\mathrm{V}_{\mathrm{T}}$, and (3) CCC off with an approximated target $\mathrm{V}_{\mathrm{T}}$. We hypothesized that accurate exhaled $\mathrm{V}_{\mathrm{T}}$ measurements could be attained using either the proximal flow sensor or the ventilator's CCC.

\section{Methods}

The Animal Review Committee of the University of Arkansas for Medical Science approved this study. Animals were cared for in accordance with the standards for care and use of laboratory animals set forth by the university. The study was a randomized crossover design, with each animal serving as its own control.

\section{Animal Experiments}

Studies were performed on 8 neonatal pigs of approximately $2 \mathrm{~kg}$ (range $1.8-2.2 \mathrm{~kg}$ ). Pigs were male, domestic porcine anesthetized with a mixture of tiletamine-zolazepam, ketamine, and xylazine $(0.04 \mathrm{~mL} / \mathrm{kg}$; intramuscular injection) and isoflurane gas (3-4\%). Pigs were intubated with a 3.0 endotracheal tube. A cuffed tube was used to ensure accuracy of the data collected. Dissection to the external jugular vein was performed, and a central venous line was placed for drug administration (midazolam [0.3$0.5 \mathrm{mg} / \mathrm{kg} / \mathrm{h}$ ] plus propofol [3-5 mg/kg/h]) during experiments. In addition, an arterial catheter was placed in the carotid artery for blood gas/blood pressure monitoring. Heart rate, oxygen saturation, and temperature were monitored with a physiologic monitor (Siemens SC 9000XL, Dräger, Lübeck, Germany). Each pig was evaluated first in the healthy state and then again following lung injury and recruitment. 
Pigs with both healthy and injured/recruited lungs were ventilated with the Servo-i ventilator, both with and without the proximal flow sensor, utilizing pressure-regulated volume control (PRVC). This is a volume-targeted mode, with varying pressure to keep $\mathrm{V}_{\mathrm{T}}$ constant. PRVC mode adjusts the peak pressure to the $V_{T}$ measured internally, irrespective of the presence of the proximal sensor. However, the displayed volume shows the $\mathrm{V}_{\mathrm{T}}$ as measured by the proximal sensor if this is being used. We used 3 methods to set $\mathrm{V}_{\mathrm{T}}$ : (1) CCC on, set $\mathrm{V}_{\mathrm{T}} 6-8 \mathrm{~mL} / \mathrm{kg}$; (2) CCC off, calculated $\mathrm{V}_{\mathrm{T}}$ using the manufacturer's circuit compliance factor; (3) CCC off, set $\mathrm{V}_{\mathrm{T}} 10-12 \mathrm{~mL} / \mathrm{kg}$ to approximate a target $\mathrm{V}_{\mathrm{T}}$ of $6-8 \mathrm{~mL} / \mathrm{kg}$. Order of the method and the presence or absence of sensor were randomized within lung status (healthy and injured lung).

To produce an injured lung model, pigs were subjected to a combined saline washout ${ }^{10}$ and ventilator-induced injury (ventilation for $1 \mathrm{~h}$ with $\mathrm{V}_{\mathrm{T}} 20 \mathrm{~mL} / \mathrm{kg}$ and zero PEEP). The saline washout was completed with volumes of $30 \mathrm{~mL} / \mathrm{kg}$ normal saline, administered in 3 back-to-back instillations through a tight tracheal cannula via gravity drainage into and out of the lungs. Lungs were considered injured when dynamic compliance, as indicated with the ventilator software, was $\leq 50 \%$ baseline, and $\mathrm{P}_{\mathrm{aO}_{2}}$ plus $\mathrm{P}_{\mathrm{aCO}_{2}}$ was $\leq 200 \mathrm{~mm} \mathrm{Hg}$. We then used a published method to set PEEP with a computerized ventilation recruitment tool $^{11}$ available on the Servo-i ventilator. Recruitment was confirmed by $\mathrm{P}_{\mathrm{aO}_{2}}$ plus $\mathrm{P}_{\mathrm{aCO}_{2}}>400 \mathrm{~mm} \mathrm{Hg}$ at $\mathrm{F}_{\mathrm{IO}_{2}} 1.0 .^{12}$ This measure corresponds to $<5 \%$ of collapsed lung on a computed axial tomography scan. ${ }^{12}$

The PEEP was set at $3 \mathrm{~cm} \mathrm{H}_{2} \mathrm{O}$ for baseline (PRVC, $\mathrm{CCC}$ on, $\mathrm{V}_{\mathrm{T}} 6-8 \mathrm{~mL} / \mathrm{kg}$; breathing frequency set to maintain $\mathrm{pH}>7.3, \mathrm{CO}_{2} 35-50$ ) and healthy lung status; for injured lung status, the PEEP level was determined as stated above. Inspiratory time was set at $0.35 \mathrm{~s}$ for both healthy and injured lung status. Flow was decelerating in PRVC. Flow triggering was used, with the trigger sensitivity kept within the green bar, indicating normal, and the high pressure alarm was set at $35 \mathrm{~cm} \mathrm{H}_{2} \mathrm{O} . \mathrm{F}_{\mathrm{IO}_{2}}$ was 1.0 for all experiments.

\section{Data Acquisition}

Measurements of respiratory flow and pressure waveforms were acquired using the Biopac MP-100 system (Biopac Systems, Santa Barbara, California). A calibrated 0-10-L/min heated pneumotachograph (catalog No. 8410, Hans Rudolph, Shawnee, Kansas) was placed in-line between the endotracheal tube and the ventilator and was the referent (accepted standard) for this study. Volume measurements were obtained through the computer by integrating the flow signal. Exhaled $\mathrm{V}_{\mathrm{T}}$ was verified with a 10-mL calibrated syringe (Hans Rudolph). Airway pressure was calibrated with a type SJ-16 vertical manometer
(Air Flow Developments Ltd, High Wycombe, United Kingdom). All output signals were routed via an analog channel box into the Biopac MP-100 data acquisition unit, converting them into digital signals that can be processed with a computer. Signals were obtained at a rate of 500 samples/s. Data were recorded for $60 \mathrm{~s}$ for each data collection point (lung status, $\mathrm{V}_{\mathrm{T}}$ setting, and with/without sensor).

Values for exhaled $V_{T}$ displayed by the ventilator were matched time-wise and compared with measurements obtained with the pneumotachograph at the airway. Displayed measurements were collected from the ventilator via a memory card. For each data collection period, we analyzed 10 consecutive animal-triggered and 10 consecutive ventilator-triggered breaths, when available. Breaths were measured consecutively unless a breath was determined to not be a true representation (ie, evidence of movement by the animal, double triggering, etc) of the majority of the breaths in the sequence. If the breath was determined to not be a true representative breath, it was skipped, and the next available breath in the time sequence was analyzed. All breaths utilized or skipped were documented.

Arterial blood gases were analyzed using a Radiometer ABL 700 blood gas analyzer (Radiometer Medical, Copenhagen, Denmark). Primary outcomes of interest were $\mathrm{P}_{\mathrm{aO}_{2}}(\mathrm{~mm} \mathrm{Hg}), \mathrm{P}_{\mathrm{aCO}_{2}}(\mathrm{~mm} \mathrm{Hg})$, and $\mathrm{pH}$. Samples were collected at each data collection point.

Ventilator parameters were downloaded from the Servo-i ventilator. Primary outcomes of interest were breathing frequency, exhaled $\mathrm{V}_{\mathrm{T}}(\mathrm{mL})$, mean airway pressure $\left(\mathrm{cm} \mathrm{H}_{2} \mathrm{O}\right)$, peak inspiratory pressure $\left(\mathrm{cm} \mathrm{H}_{2} \mathrm{O}\right)$, and dynamic and static compliance $\left(\mathrm{mL} / \mathrm{cm} \mathrm{H}_{2} \mathrm{O}\right)$. Data were collected for each period (lung status, $\mathrm{V}_{\mathrm{T}}$ setting, and with/without sensor).

Hemodynamic parameters were monitored continuously with a physiologic monitor (Siemens SC 9000XL). Primary hemodynamic outcomes of interest were mean arterial blood pressure $(\mathrm{mm} \mathrm{Hg})$ and heart rate (beats/min).

\section{Data Analysis}

Key variables, such as heart rate, mean arterial blood pressure, breathing frequency, mean airway pressure, peak inspiratory pressure, and $\mathrm{pH}$, were compared between the healthy and injured lung models using paired tests. To assess agreement, exhaled $\mathrm{V}_{\mathrm{T}}$ percentage error and concordance correlation coefficients were reported for with and without the sensor within the 3 methods. Exhaled $V_{\mathrm{T}}$ percentage error was calculated as [(ventilator displayed value - pneumotachograph-measured value)/pneumotachograph-measured value] $\times 100$. Exhaled $V_{T}$ percentage error between sensor on and off was compared using paired $t$ tests. The concordance correlation coefficient is a standardized statistic and was used to measure the amount of agreement 
Table 1. Summary Statistics and Comparison of Heart Rate, Mean Arterial Pressure, Breathing Frequency, Mean Airway Pressure, Peak Inspiratory Pressure, and pH Between the Healthy and Injured/Recruited Lung Models

\begin{tabular}{lccc}
\hline \hline \multicolumn{1}{c}{ Variable } & $\begin{array}{c}\text { Healthy } \\
\text { Lung }\end{array}$ & $\begin{array}{c}\text { Injured/Recruited } \\
\text { Lung }\end{array}$ & $P$ \\
\hline Heart rate, beats/min & $144.5 \pm 28.9$ & $161.9 \pm 46.8$ & $<.001$ \\
$\mathrm{MAP}, \mathrm{mm} \mathrm{Hg}$ & $69.3 \pm 7.8$ & $69.6 \pm 9.8$ & .81 \\
$\mathrm{f}$, breaths $/ \mathrm{min}$ & $35.2 \pm 5.9$ & $48.9 \pm 7.3$ & $<.001$ \\
$\mathrm{P}_{\mathrm{aw}}, \mathrm{cm} \mathrm{H}_{2} \mathrm{O}$ & $5.6 \pm 2.4$ & $16.0 \pm 4.3$ & $<.001$ \\
$\mathrm{PIP}, \mathrm{cm} \mathrm{H}_{2} \mathrm{O}$ & $12.2 \pm 6.7$ & $25.8 \pm 7.2$ & $<.001$ \\
$\mathrm{pH}$ & $7.39 \pm 0.05$ & $7.22 \pm 0.10$ & $<.001$ \\
& & & \\
\hline Results are mean \pm SD. $P$ values from paired $t$ tests comparing means between 2 lung models \\
are reported.
\end{tabular}

between ventilator-displayed and pneumotachographmeasured values. Concordance correlation ranges between -1 and 1 , with -1 being the perfect negative agreement, 1 being the perfect positive agreement, and 0 being no agreement. The $95 \%$ CIs for concordance correlation coefficients were also calculated. Bland-Altman plots to assess bias and precision were constructed for the difference plotted against the mean exhaled $\mathrm{V}_{\mathrm{T}}$ (ventilator-displayed and pneumotachograph-measured), utilizing all measured data points. The bias is the mean difference $(\mathrm{mL})$ in the ventilator-displayed $\mathrm{V}_{\mathrm{T}}$ and the pneumotachograph-measured $\mathrm{V}_{\mathrm{T}}$, and precision is the variance.

Results are presented as mean \pm SD. Statistical significance was defined as $P<.05$. All statistical analysis were conducted using Stata 14.0 (StataCorp, College Station, Texas). Bland-Atlman plots were produced using SPSS 16.0 (SPSS, Chicago, Illinois).

\section{Results}

Mean piglet weight was $1.9 \pm 0.1 \mathrm{~kg}$. The mean arterial blood pressure did not differ significantly between healthy and injured/recruited lung models. Heart rate, breathing frequency, mean airway pressure, and peak inspiratory pressure were increased for injured/recruited lungs $(P<.001)$ (Table 1$) ; \mathrm{pH}$ was decreased $(P=.001)$. There were no differences in mean peak inspiratory pressure between CCC on $\left(20 \pm 5 \mathrm{~cm} \mathrm{H}_{2} \mathrm{O}\right)$ and $\mathrm{CCC}$ off $\left(19 \pm 5 \mathrm{~cm} \mathrm{H}_{2} \mathrm{O}\right)$ or with the sensor $\left(19 \pm 4 \mathrm{~cm} \mathrm{H}_{2} \mathrm{O}\right)$ and without the sensor $\left(20 \pm 6 \mathrm{~cm} \mathrm{H}_{2} \mathrm{O}\right)$.

Mean compliance was $2 \pm 1$ (dynamic) and $3 \pm 1$ (static) $\mathrm{mL} / \mathrm{cm} \mathrm{H}_{2} \mathrm{O}$ for the healthy lung at baseline and $1 \pm 0.3$ (dynamic) and $1 \pm 0.2$ (static) for the injured lung. Mean $\mathrm{P}_{\mathrm{aO}}$ plus $\mathrm{P}_{\mathrm{aCO}}$ was $560 \pm 30 \mathrm{~mm} \mathrm{Hg}$ at baseline and $103 \pm 45 \mathrm{~mm} \mathrm{Hg}$ for the injured lung. Mean $\mathrm{P}_{\mathrm{aO}_{2}}$ plus $\mathrm{P}_{\mathrm{aCO}_{2}}$ was $435 \pm 60 \mathrm{~mm} \mathrm{Hg}$ for the recruited lung.

Table 2 summarizes the exhaled $V_{T}$ percentage error and the concordance correlation coefficients for all study states. Sensor use resulted in a positive error with CCC on, whereas without the sensor, error was similar but negative. With CCC off, use of the sensor markedly reduced exhaled $\mathrm{V}_{\mathrm{T}}$ percentage error. Concordance correlation coefficients were highest for CCC without sensor use in the healthy lung, but in the injured lung, use of the sensor increased concordance with the pneumotachograph readings in all cases but especially if CCC was off. Table 3 summarizes the percentage error of the pneumotachograph compared with the set $\mathrm{V}_{\mathrm{T}}$ for all methods. None was significant.

Bland-Altman plots are shown in Figures 1-3. Figure 1 shows results for $\mathrm{CCC}$ on, comparing the sensor on versus sensor off for both the healthy (top) and injured/recruited (bottom) lung models. There is a positive bias with the sensor on and a negative bias with the sensor off in both the healthy and lung-injured models. Precision is improved without the sensor. Figure 2 shows results for CCC off (calculated $\mathrm{V}_{\mathrm{T}}$ ), where it can be seen that the use of the sensor improves both accuracy and precision, markedly so in the injured/recruited model. Figure 3 shows results for CCC off $\left(\mathrm{V}_{\mathrm{T}} 10-12 \mathrm{~mL} / \mathrm{kg}\right)$, which are similar to those with the calculated $\mathrm{V}_{\mathrm{T}}$. Again, there is improvement in accuracy and precision with the use of the sensor, markedly so in the injured/recruited model. An overall positive bias can also be seen in both plots, indicating that displayed exhaled $\mathrm{V}_{\mathrm{T}}$ is greater than measured.

\section{Discussion}

\section{Main Results}

When the flow sensor was not in place, the use of CCC improved the overall accuracy of the ventilator-displayed exhaled $\mathrm{V}_{\mathrm{T}}$ in both healthy and lung-injured/recruited models compared with CCC off. This improvement was much more marked in the injured/recruited model, where use of the in-line flow sensor improved precision in all cases, especially when CCC was turned off. However, measurements with CCC on were more precise when the proximal flow sensor was not in place. Our study results thus demonstrate that exhaled $\mathrm{V}_{\mathrm{T}}$ can be accurately measured either at the airway with a flow sensor or at the expiratory valve of the ventilator using current CCC software. Without the flow sensor, exhaled $\mathrm{V}_{\mathrm{T}}$ measurements at the expiratory valve of the ventilator become inaccurate and variable when CCC software is not used.

\section{Relevance of the Study}

Several previous clinical studies using the older Servo 300 ventilator have reported poor correlation between ven- 


\section{Reliability of Displayed $V_{\mathrm{T}}$ IN Piglets}

Table 2. Exhaled Tidal Volume Percentage Error and Significance, Concordance Correlation Coefficient, and 95\% CI Comparing With or Without a Sensor Within the 3 Methods

\begin{tabular}{|c|c|c|c|c|c|c|}
\hline \multirow{2}{*}{ Lung Status } & \multirow{2}{*}{$\begin{array}{l}\text { Method to Achieve } \\
\text { Target } V_{T}\end{array}$} & \multicolumn{3}{|c|}{ Exhaled $\mathrm{V}_{\mathrm{T}} \%$ Error $\pm \mathrm{SD}$} & \multicolumn{2}{|c|}{$\begin{array}{l}\text { Concordance Correlation } \\
\text { Coefficient }(95 \% \text { CI) }\end{array}$} \\
\hline & & Without Sensor & With Sensor & $P$ & Without Sensor & With Sensor \\
\hline \multirow[t]{3}{*}{ Healthy } & $\mathrm{CCC}$ on $(6-8 \mathrm{~mL} / \mathrm{kg})$ & $-13.5 \pm 4.8$ & $15.9 \pm 11.0$ & $<.001$ & $0.70(0.63-0.76)$ & $0.45(0.36-0.54)$ \\
\hline & CCC off (calculated $\mathrm{V}_{\mathrm{T}}$ ) & $20.4 \pm 15.5$ & $8.1 \pm 15.1$ & $<.001$ & $0.44(0.34-0.53)$ & $0.62(0.52-0.73)$ \\
\hline & CCC off $(10-12 \mathrm{~mL} / \mathrm{kg})$ & $27.8 \pm 17.9$ & $17.3 \pm 9.2$ & $<.001$ & $0.22(0.13-0.31)$ & $0.47(0.38-0.57)$ \\
\hline \multirow[t]{3}{*}{ Injured/Recruited } & $\mathrm{CCC}$ on $(6-8 \mathrm{~mL} / \mathrm{kg})$ & $-11.9 \pm 4.9$ & $13.4 \pm 13.5$ & $<.001$ & $0.62(0.54-0.70)$ & $0.67(0.56-0.77)$ \\
\hline & CCC off (calculated $\mathrm{V}_{\mathrm{T}}$ ) & $77.9 \pm 24.8$ & $8.0 \pm 14.0$ & $<.001$ & $0.12(0.08-0.16)$ & $0.70(0.60-0.80)$ \\
\hline & CCC off $(10-12 \mathrm{~mL} / \mathrm{kg})$ & $69.6 \pm 34.0$ & $17.8 \pm 13.5$ & $<.001$ & $0.06(0.02-0.10)$ & $0.54(0.43-0.65)$ \\
\hline \multicolumn{7}{|c|}{$\begin{array}{l}\text { Exhaled tidal volume percentage error is calculated as the }[(\text { ventilator-displayed value }- \text { pneumotachograph-measured value }) / \text { pneumotachograph-measured value }] \times 100 . P \text { values from paired } t \text { tests } \\
\text { comparing average exhaled tidal volume percentage error between without sensor and with sensor are reported. } \\
\mathrm{V}_{\mathrm{T}}=\text { tidal volume } \\
\mathrm{CCC}=\text { circuit compliance compensation }\end{array}$} \\
\hline
\end{tabular}

Table 3. Pneumotachograph Percentage Error and Significance, Concordance Correlation Coefficient, and 95\% CI Comparing With or Without a Sensor Within the 3 Methods

\begin{tabular}{|c|c|c|c|c|c|c|}
\hline \multirow{2}{*}{ Lung Status } & \multirow{2}{*}{$\begin{array}{l}\text { Method to Achieve } \\
\text { Target } \mathrm{V}_{\mathrm{T}}\end{array}$} & \multicolumn{3}{|c|}{$\mathrm{PNT} \%$ Error $\pm \mathrm{SD}$} & \multicolumn{2}{|c|}{$\begin{array}{c}\text { Concordance Correlation } \\
\text { Coefficient }(95 \% \text { CI })\end{array}$} \\
\hline & & Without Sensor & With Sensor & $P$ & Without Sensor & With Sensor \\
\hline \multirow[t]{3}{*}{ Healthy } & $\mathrm{CCC}$ on $(6-8 \mathrm{~mL} / \mathrm{kg})$ & $17.92 \pm 13.41$ & $21.75 \pm 14.65$ & .24 & $0.60(0.31-0.89)$ & $0.39(0.06-0.72)$ \\
\hline & CCC off (calculated $\mathrm{V}_{\mathrm{T}}$ ) & $-15.02 \pm 14.95$ & $-12.74 \pm 18.14$ & .41 & $0.33(-0.04$ to 0.70$)$ & $0.28(-0.17$ to 0.72$)$ \\
\hline & CCC off $(10-12 \mathrm{~mL} / \mathrm{kg})$ & $-20.25 \pm 14.72$ & $-20.71 \pm 9.18$ & .41 & $0.15(-0.12$ to 0.43$)$ & $0.23(-0.06$ to 0.51$)$ \\
\hline \multirow[t]{3}{*}{ Injured/Recruited } & $\mathrm{CCC}$ on $(6-8 \mathrm{~mL} / \mathrm{kg})$ & $8.89 \pm 8.70$ & $10.37 \pm 8.60$ & .64 & $0.71(0.37-1.06)$ & $0.77(0.53-1.00)$ \\
\hline & CCC off (calculated $V_{T}$ ) & $-45.05 \pm 7.38$ & $-43.25 \pm 10.30$ & .56 & $0.11(-0.01$ to 0.23$)$ & $0.09(-0.03$ to 0.21$)$ \\
\hline & CCC off $(10-12 \mathrm{~mL} / \mathrm{kg})$ & $-41.04 \pm 13.49$ & $-45.47 \pm 8.69$ & .47 & $0.05(-0.08$ to 0.17$)$ & $0.04(-0.04$ to 0.11$)$ \\
\hline \multicolumn{7}{|c|}{$\begin{array}{l}\text { Percentage error is calculated as the }\left[\left(\text { pneumotachograph-measured exhaled } \mathrm{V}_{\mathrm{T}}-\text { set } \mathrm{V}_{\mathrm{T}}\right) / \text { set } \mathrm{V}_{\mathrm{T}}\right] \times 100 . P \text { values from paired } t \text { tests comparing average pneumotachograph percentage error between } \\
\text { without sensor and with sensor are reported. } \\
\text { PNT = pneumotachograph } \\
\text { CCC }=\text { circuit compliance compensation }\end{array}$} \\
\hline
\end{tabular}

tilator-displayed exhaled $\mathrm{V}_{\mathrm{T}}$ measurements and those measured at the proximal airway. Castle et $\mathrm{al}^{7}$ studied 56 infants and children and found an overestimation of displayed exhaled $V_{T}$ by the Servo 300 ventilator of up to $91 \%$. After correcting for gas compression, the ventilator underestimated the true exhaled $\mathrm{V}_{\mathrm{T}}$ by up to $64 \%$ in the smallest infants and overestimated by up to $29 \%$ in the older population. Using the same ventilator, Cannon et al ${ }^{13}$ looked at the accuracy of exhaled $\mathrm{V}_{\mathrm{T}}$ measured at the ventilator compared with a pneumotachometer at the airway and also found poor correlation between the measurements $\left(r^{2}=0.54\right.$ in the infant circuit). Our study results agree with the overestimation of the displayed exhaled $V_{T}$ measured by the ventilator when CCC is not used. The newer Servo-i ventilator's CCC software may account for the improvement in accuracy. Similarly, sensor design may account for the positive bias and imprecision compared with the pneumotachograph. Differences in bias and precision with various sensors have been reported previously. ${ }^{14}$

In vitro studies have also been done using test lungs to evaluate $V_{T}$ delivery and exhaled $V_{T}$ measurement in ventilators. Bachiller et al ${ }^{15}$ aimed to compare several ventilators' ability to accurately measure and deliver a set $\mathrm{V}_{\mathrm{T}}$ to both infant and adult test lungs using volume control ventilation. This study compared several different ventilators: 2 with and 2 without CCC. The ventilators with CCC displayed exhaled $\mathrm{V}_{\mathrm{T}}$ with an error of $<9 \%$, whereas the error was up to $50 \%$ in displayed exhaled $\mathrm{V}_{\mathrm{T}}$ without CCC. They also found that the error was higher in the smaller volume test lungs $(\leq 200 \mathrm{~mL})$. This study differs from ours in that they compared measurements across several different ventilators; however, our results are similar. In addition, this study compared the delivered $\mathrm{V}_{\mathrm{T}}$ to the set $\mathrm{V}_{\mathrm{T}}$ and found that the ventilators with CCC delivered $95.5-106.2 \%$ of the set $\mathrm{V}_{\mathrm{T}}$ 

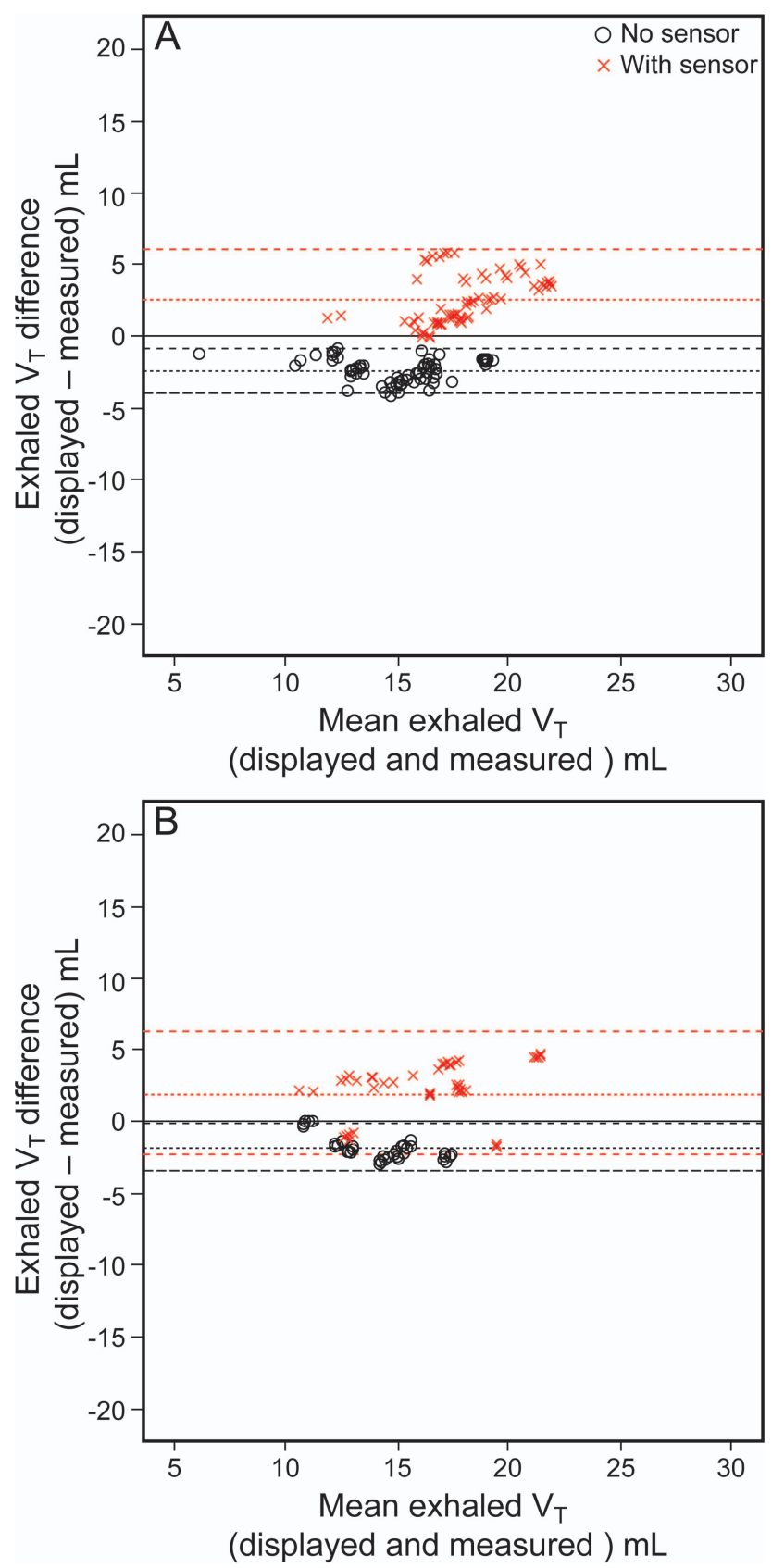

Fig. 1. Bland-Altman plots with exhaled $V_{T}$ difference plotted against the mean (displayed and pneumotachograph-measured) with and without sensor for method circuit compliance compensation on (set $\mathrm{V}_{\mathrm{T}} 6-8 \mathrm{~mL} / \mathrm{kg}$ ). Center lines denote mean difference, and outside lines show $\pm 2 \mathrm{SD}$. A: healthy lung model. B: injured/recruited lung model.

to the patient, compared with $45.6-109.3 \%$ without CCC.

Our study expands on the findings reported previously by Heulitt et al, ${ }^{8}$ which also demonstrated the improved accuracy of exhaled $\mathrm{V}_{\mathrm{T}}$ measurements at the exhaled valve of the ventilator with the use of CCC software, using a pig model. However, our study had several differences. Heu-
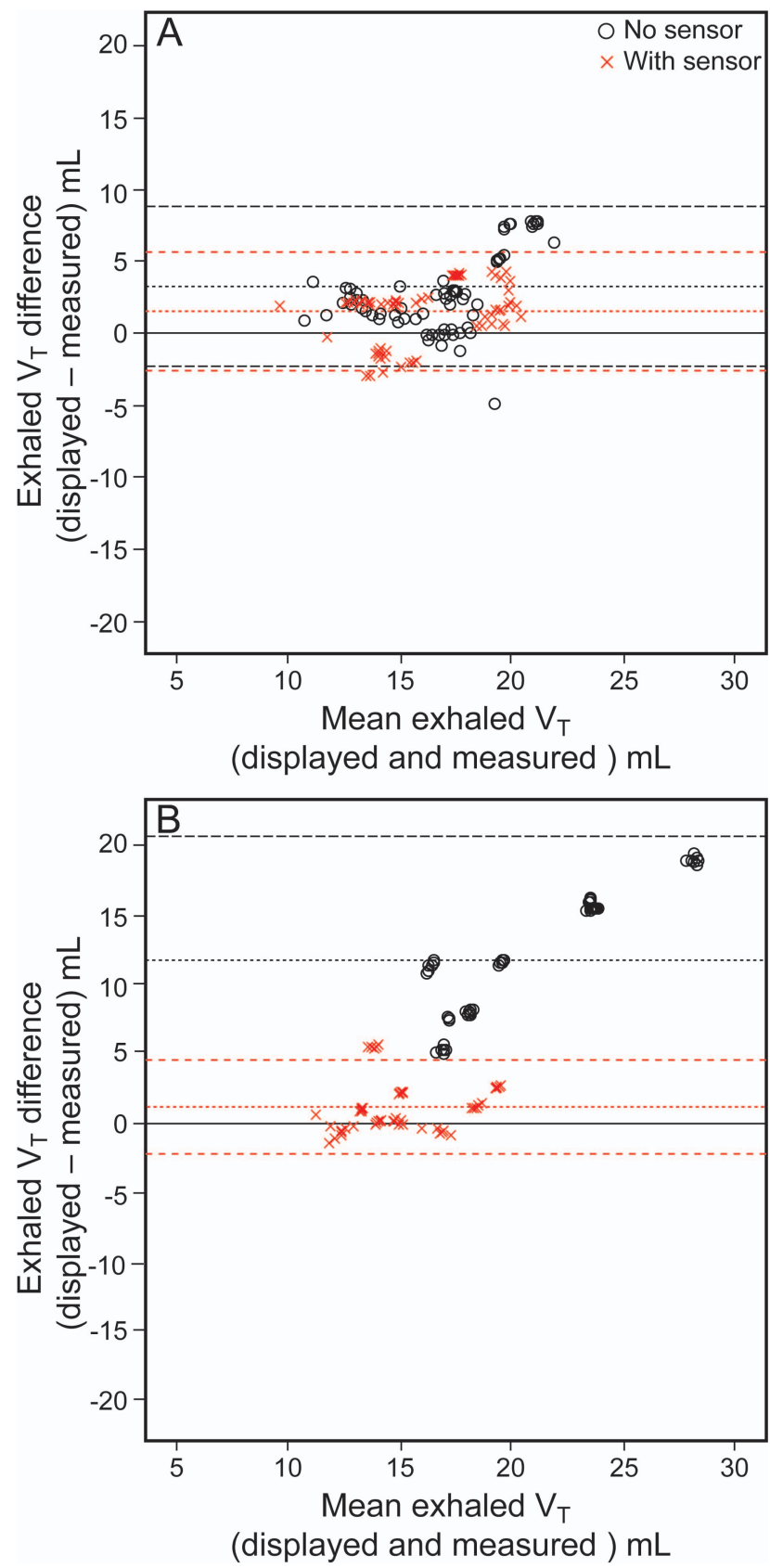

Fig. 2. Bland-Altman plots with exhaled $V_{T}$ difference plotted against the mean (displayed and pneumotachograph-measured) with and without sensor for method circuit compliance compensation off (calculated $\mathrm{V}_{\mathrm{T}}$ ). Center lines denote mean difference, and outside lines show $\pm 2 \mathrm{SD}$. A: healthy lung model. $\mathrm{B}$ : injured/recruited lung model.

litt et al included both neonatal and pediatric pigs, whereas our study focuses on the neonatal population. Our study also differed in ventilation mode: Heulitt et al ${ }^{8}$ used pressure support ventilation plus PEEP, whereas our pigs were ventilated using PRVC (chosen because this is a common mode of ventilation used in neonatal ICU patients). Moreover, our study included the surfactant-depleted model in 

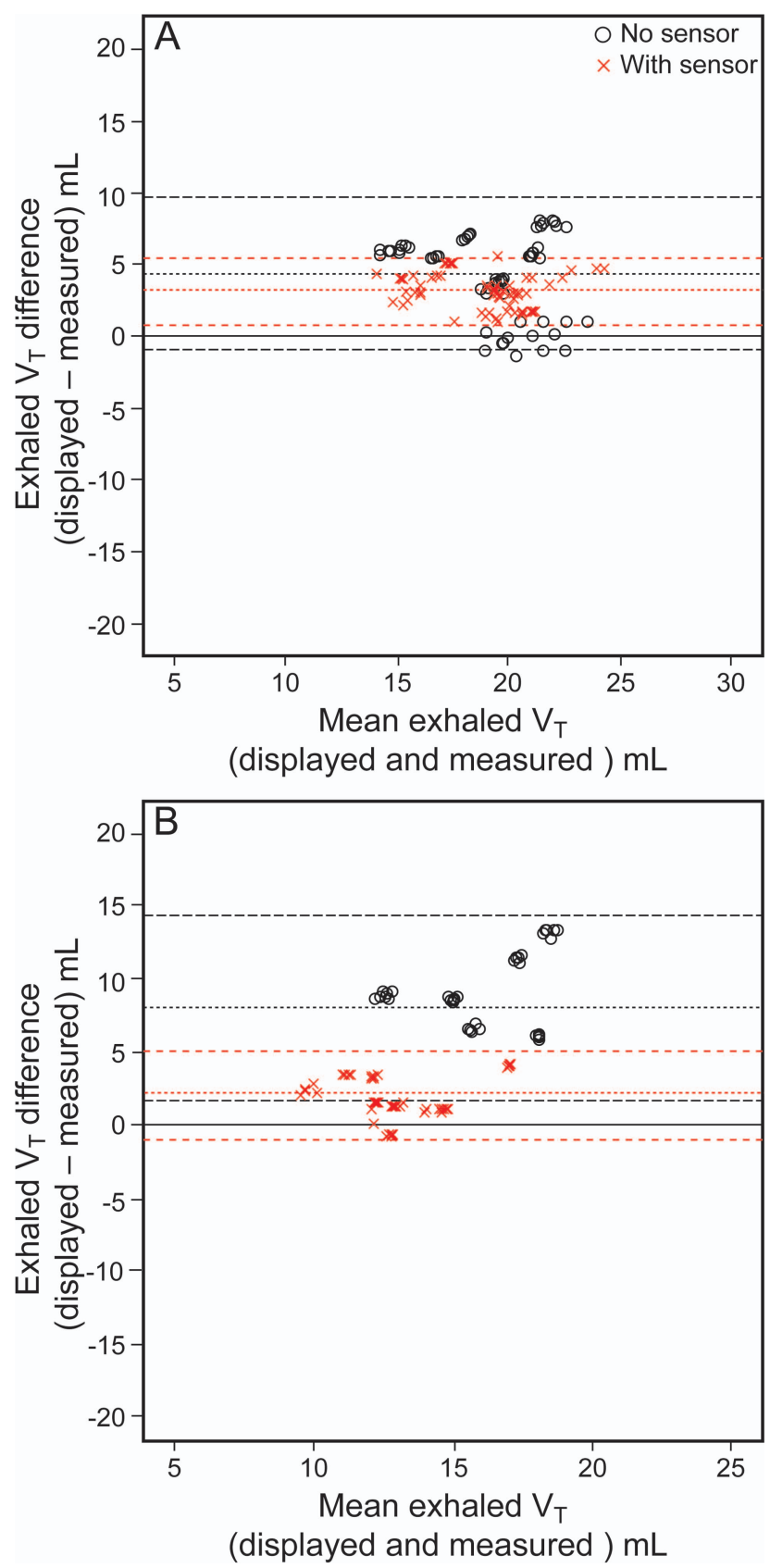

Fig. 3. Bland-Altman plots with exhaled $V_{T}$ difference plotted against the mean (displayed and pneumotachograph measured) with and without sensor for method circuit compliance compensation off (set $\mathrm{V}_{\mathrm{T}} 10-12 \mathrm{~mL} / \mathrm{kg}$ ). Center lines denote mean difference, and outside lines show $\pm 2 \mathrm{SD}$. A: healthy lung model. B: injured/recruited lung model.

addition to the healthy lung model, which is more representative of the neonatal ICU population commonly ventilated. Although our study also found that the use of CCC improved the accuracy of exhaled $\mathrm{V}_{\mathrm{T}}$ measurements in the healthy lung model, we additionally confirmed these findings in the surfactant-depleted model. Finally, our study differed in that we included an in-line sensor recently developed for the Servo-i ventilator.

The more recent clinical study by Heulitt et $\mathrm{al}^{9}$ looked at the reliability of exhaled $\mathrm{V}_{\mathrm{T}}$ measurements in subjects in the pediatric ICU, who were ventilated using PRVC, volume support ventilation, or both. This study differed from ours, because it used an older patient population with a median weight of $14.5 \mathrm{~kg}$ (range $2.3-103 \mathrm{~kg}$ ) and found no improvement in displayed exhaled $\mathrm{V}_{\mathrm{T}}$ using $\mathrm{CCC}$ in the smaller infants and children. The authors did find good overall agreement between exhaled $\mathrm{V}_{\mathrm{T}}$ measured at the subject's airway and that displayed by the ventilator. This study also reported an overestimation of displayed exhaled $\mathrm{V}_{\mathrm{T}}$ with $\mathrm{CCC}$ off and an underestimation of displayed exhaled $\mathrm{V}_{\mathrm{T}}$ with $\mathrm{CCC}$ on. These findings were duplicated in our study in the experiments with the sensor off, although our study showed a much higher percentage error and overestimation with CCC off, in particular in the surfactant-depleted model. The larger inaccuracies in the injured model can be explained by the lower compliance and higher resistance compared with the healthy model. These factors likely cause greater volume loss in the circuit and in the ventilator internal tubing, resulting in a larger error due to the compression volume of the circuit.

\section{Study Limitations}

Our study had several potential limitations. We used an animal model; thus, our results may differ if these experiments were performed on neonatal patients. The piglet model requires a larger $\mathrm{V}_{\mathrm{T}}$ than that of a comparable human patient. Additionally, our animal size was generous for a premature neonatal model; however, neonatal piglets can only be separated from the sow at about $3 \mathrm{~d}$ old. Thus, studying smaller animals is quite difficult and not financially or experimentally feasible. In addition, to prevent animal distress, we had to sedate our lung-injured pigs significantly, thus decreasing, although not eliminating, their spontaneous breaths. Animal and ventilator-triggered breaths were thus included in the analyses. Although more spontaneous breaths were included in the healthy lung status, patients with significant lung disease are often spontaneously breathing. Although there is no reason to believe that accuracy would be different for spontaneous versus ventilator breaths, we did not analyze these breaths separately.

In addition, we used cuffed endotracheal tubes for optimal accuracy of the exhaled $\mathrm{V}_{\mathrm{T}}$ measurements. Uncuffed tubes, which are often the standard in the intensive care nursery, may introduce even larger inaccuracies in exhaled $\mathrm{V}_{\mathrm{T}}$ measurements, depending on the degree of leak. However, to ensure that our volume differences were due to study parameters and not a leak, use of cuffed tubes was 
necessary. Uncuffed tubes create a variable leak, which is a confounder that makes data interpretation very difficult. Finally, although the ventilator and mode we studied are commonly employed in the neonatal ICU, other ventilators that may be configured similarly to the Servo-i may show somewhat different results.

\section{Clinical Relevance and Implications}

Although the benefits of volume-targeted ventilation in the neonatal population are well-documented, uncertainty remains regarding the best method to measure $\mathrm{V}_{\mathrm{T}}$ delivery to the patient, which is crucial to accomplishing lungprotective ventilation. Our study shows improvement in exhaled $\mathrm{V}_{\mathrm{T}}$ measurements with the use of CCC software or with the use of an in-line flow sensor in the Servo-i ventilator. More importantly, in the surfactant-depleted lung-injured model, which represents the majority of the ventilated patients in the neonatal ICU, there is a very large error in displayed exhaled $\mathrm{V}_{\mathrm{T}}$ as well as significant variability if CCC or a proximal flow sensor is not used. This inability of the clinician to know the actual $\mathrm{V}_{\mathrm{T}}$ delivered to the patient puts the patient at risk for over- or underventilation, which defeats the purpose of using volume-targeted ventilation.

Clearly, either the in-line flow sensor or the CCC option should be used for accurate $\mathrm{V}_{\mathrm{T}}$ delivery. There are clinical circumstances where one option or the other may be preferred. The flow sensor adds extra dead space and weight; thus, if weight, dead space, or pull on the ETT are issues, such as when $\mathrm{P}_{\mathrm{ETCO}_{2}}$ monitors are used or during airway surgery, the addition of a flow sensor may not be appropriate. Additionally, if secretions are a significant issue or if aerosols must be given, the flow sensor must be removed.

Use of the flow sensor is preferred, however, in some circumstances. If the infant is very small, requiring set $\mathrm{V}_{\mathrm{T}}$ values of $\leq 5 \mathrm{~cm}^{3}$, the flow sensor is recommended by the manufacturer. ${ }^{16}$ If inhaled nitric oxide is used, the sampling line for the inhaled nitric oxide, which is located near the ETT on the inspiratory limb of the circuit, will result in inaccuracies of the delivered compared with set $\mathrm{V}_{\mathrm{T}}$ and will indicate a leak when none may be present. For small infants with uncuffed ETTs, these issues can be significant. In this circumstance, use of the proximal flow sensor will allow more accurate $\mathrm{V}_{\mathrm{T}}$ delivery and more accurate leak assessment.

\section{Conclusions}

Our study shows that the use of CCC software improves the accuracy and precision of displayed exhaled $\mathrm{V}_{\mathrm{T}}$ measurements. If CCC software is not used, an in-line sensor must be placed to avoid inaccurate and imprecise mea- surements. This is particularly true in the surfactant-depleted, injured lung. Further studies may be beneficial in a smaller animal model with smaller $\mathrm{V}_{\mathrm{T}}$ values, in the presence of leak, and with other similar ventilators, to test the generalizability of these results to other populations of infants.

\section{REFERENCES}

1. Slutsky AS. Ventilator-induced lung injury: from barotrauma to biotrauma. Respir Care 2005;50(5):646-659.

2. Erickson SJ, Grauaug A, Gurrin L, Swaminathan M. Hypocarbia in the ventilated preterm infant and its effect on intraventricular haemorrhage and bronchopulmonary dysplasia. J Paediatr Child Health 2002;38(6):560-562.

3. Wheeler KI, Klingenberg C, Morley CJ, Davis PG. Volume-targeted versus pressure-limited ventilation for preterm infants: a systemic review and meta-analysis. Neonatology 2011;100(3): 219-227.

4. Singh J, Sinha SK, Clarke P, Byrne S, Donn SM. Mechanical ventilation of very low birth weight infants: is volume or pressure a better target variable? J Pediatr 2006;149(3):308-313.

5. Keszler M. State of the art in conventional mechanical ventilation. J Perinatol 2009;29(4):262-275.

6. Toyama H, Endo Y, Ejima Y, Matsubara M, Kurosawa S. Comparison of actual tidal volume in neonatal lung model volume control ventilation using three ventilators. Anaesth Intensive Care 2011; 39(4):599-606.

7. Castle RA, Dunne CJ, Mok Q, Wade AM, Stocks J. Accuracy of displayed values of tidal volume in the pediatric intensive care unit. Crit Care Med 2002;30(11):2566-2574.

8. Heulitt MJ, Holt SJ, Thurman TL, Hall RA, Jo CH, Simpson P. Reliability of measured tidal volume in mechanically ventilated young pigs with normal lungs. Intensive Care Med 2005;31(9): 1255-1261.

9. Heulitt MJ, Thurman TL, Holt SJ, Jo CH, Simpson P. Reliability of displayed tidal volume in infants and children during dual-controlled ventilation. Pediatr Crit Care Med 2009;10(6):661-667.

10. Lachmann B, Robertson B, Vogel J. In vivo lung lavage as an experimental model of the respiratory distress syndrome. Acta Anaesth Scand 1980;24(3):231-236.

11. Hanson A, Göthberg S, Nilsson K, Larsson LE, Hedenstierna G. VTCO2 and dynamic compliance-guided lung recruitment in surfactant-depleted piglets: a computed tomography study. Pediatr Crit Care Med 2009;10(6):687-692.

12. Borges JB, Okamoto VN, Matos GF, Caramez MP, Arantes PR, Barros F, Souza CE, Victorino JA, Kacmarek RM, Barbas CS, Carvalho CR, Amato MB. Reversibility of lung collapse and hypoxemia in early acute respiratory distress syndrome. Am J Respir Crit Care Med 2006;174(3):268-278.

13. Cannon ML, Cornell J, Tripp-Hamel DS, Gentile MA, Hubble CL, Meliones JN, Cheifetz IM. Tidal volumes for ventilated infants should be determined with a pneumotachometer placed at the endotracheal tube. Am J Respir Crit Care Med 2000;162(6): 2109-2112.

14. Heulitt MJ, Holt SJ, Thurman TL. Accuracy of small tidal volume measurement comparing two ventilator airway sensors. J Pediatr Intensive Care 2013;2(1):33-38.

15. Bachiller PR, McDonough JM, Feldman JM. Do new anesthesia ventilators deliver small tidal volumes accurately during volumecontrolled ventilation? Anesth Analg 2008;106(5):1392-1400, table of contents.

16. Maquet SERVO Education Study Guide, version 1.14, p 346. 